\title{
Mecanismos fisiopatológicos relacionados con la infección por SARS-CoV-2 en las personas expuestas durante 2019 y 2020
}

\section{Pathophysiological Mechanisms Related to SARS-CoV-2 Infection in People Exposed During 2019 and 2020}

Recibido: 27 Noviembre 2020 | Aceptado: 13 Abril 2021

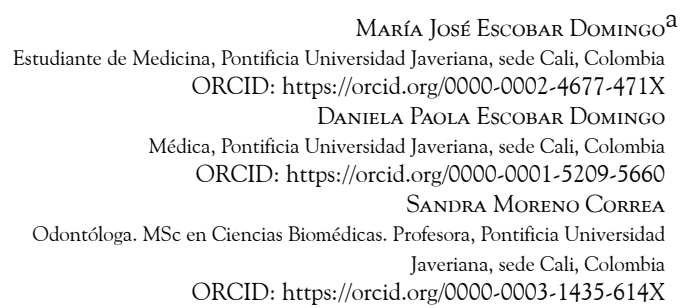

\section{RESUMEN}

El artículo describe los mecanismos fisiopatológicos relacionados con la infección por el coronavirus de 2019 (COVID-19 o SARS-CoV-2). Este, descubierto en Wuhan (China), presentó una transmisión zoonótica y, luego, comenzó a transmitirse entre humanos a través de aerosoles y superficies contaminadas con un índice alto de contagio que desató una pandemia. A través de búsqueda sistemática en Medline y Embase, se seleccionaron los estudios que apuntan al objetivo general. Se discute sobre el genoma, la estructura, el receptor celular, la respuesta inmune y la diseminación hacia otros tejidos. En conclusión, en el virus analizado hay factores que inciden en la severidad de la manifestación clínica y en la predisposición de los adultos mayores o con comorbilidades a presentar fenómenos inflamatorios generalizados. Aunque existe evidencia del virus en el sistema nervioso central, se requieren estudios que profundicen en su acción sobre este y otros tejidos.

Palabras clave

COVID-19; SARS-CoV-2; coronavirus; fisiopatología; mecanismos; infecciones por coronavirus.

a Autora de correspondencia: mjescobard@javerianacali.edu.co

Cómo citar: Escobar Domingo MJ, Escobar Domingo DP, Moreno Correa S. Mecanismos fisiopatológicos relacionados con la infección por SARS-CoV-2 en las personas expuestas durante 2019 y 2020. Univ. Med. 2021;62(3). https://doi.org/10.11144/Javeriana.umed 62-3.mfri

\section{ABSTRACT}

This review describes the pathophysiological mechanisms related to the 2019 Coronavirus infection (COVID-19 or SARS-CoV-2). This virus, discovered in Wuhan-China, had a zoonotic transmission and was later transmitted between humans through aerosols and contaminated surfaces with a high rate of contagion, triggering a Pandemic. Through systematic search in Medline and Embase, studies that point to the general objective were selected. The genome, structure, cell receptor, immune response and spread to other tissues are discussed. In conclusion, the analyzed virus presents factors that influence the severity of the clinical manifestation and the predisposition of older adults and/or comorbidities to present generalized inflammatory phenomena. Although there is evidence of viral presence in the CNS, studies are required to deepen the action of the virus on this and other tissues. 
Keywords

COVID-19; SARS-CoV-2; coronavirus; physiopathology; mechanisms; coronavirus infections.

\section{Introducción}

Los coronavirus $(\mathrm{CoV})$ hacen parte de la familia Coronaviridae y de la subfamilia Orthocoronavirinae, la cual incluye los siguientes géneros: Alphacoronavirus, Betacoronavirus, Gammacoronavirus . Deltacoronavirus (1). En las últimas dos décadas han tomado lugar tres epidemias por parte de diferentes virus del género Betacoronavirus. En 2002 emergió el coronavirus del síndrome respiratorio agudo severo (SARS$\mathrm{CoV})$, que causó 916 muertes mundialmente, es decir, causó un $10 \%$ de mortalidad en la población infectada. Posteriormente, en 2012 se identificó el coronavirus del síndrome respiratorio del Medio Oriente (MERS-CoV), que dejó 513 infectados fallecidos, lo cual corresponde al $35 \%$ de mortalidad $(1,2)$. A finales de 2019, se encontró en China un nuevo coronavirus relacionado con los anteriores, llamado SARS-CoV-2, causante de la enfermedad COVID-19. El primer caso fue reportado en Wuhan (Hubei, China), donde los principales infectados vivían alrededor del mercado de mariscos (1). La transmisión de los primeros casos pudo haber sido a través de exposición zoonótica o ambiental. Sin embargo, el crecimiento de la epidemia se presenta secundario a la transmisión de humano a humano, ya sea por contacto directo o aerosoles (2,3). Para el 27 de noviembre de 2020 había más de 61.894 .000 casos, 1.447 .000 fallecidos y 220 países afectados (4).

Comprender la fisiopatología implicada en las infecciones y complicaciones por el SARSCoV-2 es necesario, por lo que el alcance de este artículo de revisión es obtener y divulgar conocimiento acerca de aspectos microbiológicos y clínicos asociados con el virus hacia la comunidad científica nacional y local, para lograr, de esta forma, aportar y mejorar los procesos de promoción, prevención y tratamiento en la atención primaria de los pacientes afectados. A lo largo del artículo se utilizan indistintamente los términos SARS-CoV-2 y COVID-19, entendiendo que el primero hace referencia al virus, y el segundo, a la enfermedad causada por dicho microrganismo (5).

A partir de lo anterior, surge la cuestión: icuáles son los mecanismos fisiopatológicos de la infección por el SARS-CoV-2 en personas expuestas durante 2019-2020? El abordaje de dicha pregunta implica comprender el tipo de virus, su estructura, sus factores de virulencia y sus mecanismos de infección y replicación. El nombre coronavirus se le atribuye gracias a su apariencia de corona (2). Son virus envueltos, no segmentados, cuyo material genético está organizado en forma de ARN de cadena simple $(1,2)$. Las infecciones por los coronavirus se limitan usualmente a las vías respiratorias superiores; sin embargo, SARSCoV, MERS-CoV y SARS-CoV-2 tienen la capacidad de infectar las vías respiratorias inferiores. Por lo tanto, se asocian con entidades más graves, por ejemplo: síndrome respiratorio severo y neumonía $(1,2)$. El $81 \%$ de los casos corresponden a casos leves, incluso asintomáticos; el $14 \%$, a enfermedad severa con dificultad respiratoria, y el $5 \%$, usualmente adultos mayores o con otras comorbilidades, críticos con falla respiratoria, shock séptico o disfunción orgánica múltiple que pueden llevar a la muerte (6). Esta revisión pretende describir los mecanismos fisiopatológicos relacionados con la infección por 2019-nCoV en las personas expuestas durante 2019 y 2020.

\section{Materiales y métodos}

Se revisaron dos bases de datos indexadas (Medline y Embase) con las palabras clave COVID-19, SARS-CoV-2, coronavirus, physiopathology, mechanisms, coronavirus infections. Desde el 3 de abril de 2020 hasta el 15 de noviembre de 2020 se seleccionaron los artículos que mejor respondieron a la pregunta de investigación. 


\section{Resultados}

En la presente revisión de la literatura se encontraron algunos estudios que describen la fisiopatología desde el punto de vista de la alteración en la respuesta inmune específica (7-18). Así mismo, detallan una respuesta inflamatoria exacerbada y una falla en los mecanismos de regulación y control inmunológicos, lo cual se ha descrito en otro tipo de infecciones y es responsable en gran medida de las complicaciones y falla en la terapéutica.

Otros estudios han analizado como punto clave la interacción entre las proteínas de la envoltura viral y el receptor celular $(3,6,7,19-34)$, lo cual permite explicar el grado de contagio del virus, de acuerdo con su afinidad por el receptor, así como su virulencia y patogenicidad sobre el tejido pulmonar.

Algunos autores, por su parte, se han dedicado a analizar la secuencia genética del virus y a compararla con el de otros coronavirus como el SARS-CoV $(3,6,10,20,26,27,31,32,34-41)$, con lo que han encontrado diferencias que impactan sobre algunas proteínas virales, lo que le da una mayor complejidad al SARS-CoV-2, en términos de transmisión. Finalmente, otros estudios se han centrado en la capacidad del virus para hacer viremia y diseminarse a tejidos, como el sistema nervioso central (SNC), riñones, corazón y endotelio, lo que los daña y se relaciona con una falla multiorgánica en pacientes complicados $(11,16,17,23,28,29,35,37,42-58)$.

\section{Discusión}

\section{Genoma y estructura viral}

Hasta el momento se conocen siete $\mathrm{CoV}$ humanos $(\mathrm{HCoV})$, cuatro de ellos producen manifestaciones leves en las vías respiratorias altas, aunque pueden estar asociados con síntomas más severos en niños y adultos mayores. Corresponden a HCoV-229E, HCoVNL63, HCoV-OC43 y HCoV-HKU1. Por otra parte, MERS-CoV, SARS-CoV y SARS-CoV-2 son capaces de infectar las vías respiratorias bajas y resultar en neumonía. Todos los $\mathrm{HCoV}$ pertenecen al género Betacoronavirus, a excepción de HCoV-229E y HCoV-NL63, los cuales hacen parte de los Alfacoronavirus(3).

Los CoV son virus envueltos, con un diámetro de 80 a $120 \mathrm{~nm}$ (35). Su genoma corresponde a un ARN de cadena simple, positiva y no segmentada (+ssARN), la cual, al contener de 26.000 a 37.000 bases, representa el genoma más largo entre los virus ARN. Su información genética se encuentra organizada de la siguiente forma: 5'-liderUTR-replicasa-proteína $S$ (espiga)-proteína $E$ (envoltura)-proteína M (membrana)-proteína $\mathrm{N}$ (nucleocápside)-3'-UTRcolapoli (A) (3,20,31). Adicionalmente, en el extremo 3' tienen lugar genes accesorios interdispersos (3).

Entre las proteínas estructurales de los $\mathrm{CoV}$ se encuentran las proteínas de membrana (M) y de envoltura (E), con roles esenciales en el ensamblaje viral (3). Por otra parte, la proteína de la nucleocápside $(\mathrm{N})$ está involucrada en la transcripción del ARN viral y junto a la proteína de superficie o espiga (S), le otorgan estabilidad al virus. Además, esta última se encarga del anclaje y la fusión a las membranas de las células blanco $(3,27)$. Homotrímeros de proteína S conforman las espigas que se encuentran sobre la envoltura viral, las cuales presentan dos subunidades: S1 y S2 $(6,26)$.

El genoma de SARS-CoV-2 está compuesto por 29.891 nucleótidos que codifican para 9860 aminoácidos (6), correspondientes a dos poliproteínas (ppla y pp1a/b), clivadas en 15/16 proteínas no estructurales (nsps) por acción de dos proteasas virales (proteasa tipo 3C o 3CLpro y proteasa tipo papaína o PLpro). Entre las nsps se incluye la polimerasa ARN dependiente de ARN (RdRp), que conforman el complejo de replicación $(20,26,59)$. Lo anterior seguido de, al menos, 13 marcos de lectura abiertos (ORF): glucoproteína de superficie, ORF3a, ORF3b, envoltura, membrana, ORF6, ORF 7a, ORF7b, ORF8, nucleocápside, ORF9a, ORF9b y ORF10 $(8,26,36,38)$, entre los cuales se encuentran secuencias reguladoras de la transcripción (6).

En relación con otros $\mathrm{CoV}$, el genoma de SARS-CoV-2 comparte una identidad del $80 \%$ 
con SARS-CoV, del $85 \%$ con bat-SL-CoVZC45, del $89 \%$ con bat-SL-CoVZXC21 y del $96 \%$ con bat-CoV-RaTG13 $(3,6,27,31,35)$. La proteína $\mathrm{N}$ de SARS-CoV-2 se conserva en un $90 \%$ con respecto a la de SARS-CoV, así como la subunidad S2 de la proteína $\mathrm{S}$ comparte un $99 \%$ de similitud con SARS-CoV, batSL-CoVZXC21 y bat-SL-CoVZC45 $(27,59)$. En cuanto al dominio de unión al receptor (RBD) de la proteína S, SARS-CoV-2 y SARS-CoV difieren en 5 de 6 residuos (38). Todo lo anterior sugiere que los $\mathrm{CoV}$ mencionados se encuentran filogenéticamente relacionados entre sí y que SARS-CoV-2 pudo haber evolucionado a partir de ellos.

La evolución del SARS-CoV-2 se presenta a causa de mutaciones que resultan de procesos de recombinación genética dados, ya sea en el huésped o al pasar de una especia a otra (3). De esta manera, variantes genéticas en proteínas fundamentales, como proteínas $\mathrm{S}$ y $\mathrm{N}$, generan que su capacidad patogénica al ser transmitidos a humanos sea mayor en comparación con los SL-CoV (coronavirus similar al SARS WIV 1 de murciélagos) y menor con respecto a SARSCoV. Lo anterior puede explicar su transmisión zoonótica y un comienzo menos severo que la epidemia por SARS $(3,40)$. En ese orden de ideas, la secuencia de aminoácidos de la proteína $S$ es la más variable, siendo su RBD el principal determinante del rango de huéspedes y la transmisión viral y ello sugiere una fuerte selección positiva de los $\mathrm{CoV}$ para adaptarse a sus huéspedes $(31,32)$. Además, se han identificado deleciones específicas en el gen de la proteína $\mathrm{S}$ que le permiten evadir la respuesta inmune (10).

Ceraolo et al. (39) encontraron dos lugares de hipervariabilidad en el genoma de SARS-CoV-2, en la posición 8789 , localizada en el gen de la poliproteína, y en la posición 28.151, ubicada en el gen ORF8 (3). Asimismo, en una comparación sistemática entre SARS-CoV-2 y SARS-CoV realizada por Xu et al. (27), a pesar de demostrar una alta homogeneidad genómica y proteica entre ambos virus, identificaron seis regiones de diferencia (RD): las primeras tres (RD1, RD2 y RD3) corresponden a secuencias codificantes de genes orf lab, las siguientes dos regiones (RD4 y RD5) son secuencias codificantes de genes S; mientras que la última región (RD6) hace parte de la secuencia de codificación de los genes orf $7 b$ y orf8 (27). Además, las proteínas 8a y orf10 del SARS-CoV-2 no presentan homólogos proteicos en SARS-CoV, en tanto que la proteína 3b está compuesta por 22 aminoácidos en el primer virus y 154 aminoácidos en el segundo, en contraste con la proteína $8 \mathrm{~b}$ más larga en el primero que en el segundo con 124 y 84 aminoácidos, respectivamente $(3,26)$.

\section{Receptor celular}

El receptor de SARS-CoV-2, en las células del huésped, corresponde a la enzima convertidora de angiotensina 2 (ECA2) (3,34). El gen ECA2 se ubica en Xp22, su tamaño es de $39,98 \mathrm{kB}$ y contiene 18 exones y 20 intrones. Por empalme alternativo se producen seis variantes, con diferencias en la actividad enzimática, por lo que es un gen altamente polimórfico (19). El producto final es una glucoproteína transmembrana tipo I, compuesta por 805 aminoácidos, organizados en un dominio extraceluar catalítico, un único dominio transmembrana y un dominio carboxilo citoplasmático. El dominio extracelular consiste en el sitio catalítico metaloproteasa de zinc y el sitio de unión a la espiga viral (20).

$\mathrm{Su}$ actividad metaloproteasa le otorga su principal función fisiológica de contrarregular el sistema renina-angiotensina-aldosterona (SRAA), mediante la degradación de angiotensina II (Ang II) en angiotensina-(1-7) y de angiotensina I (Ang I) en angiotensina-(1-9), siendo el efecto catalítico sobre Ang II 400 veces mayor que sobre Ang I. Los péptidos generados por la actividad de ECA2, Ang (1-9) y Ang (1-7) se unen al receptor Mas, un receptor asociado a la proteína $G(20-22,33)$. Su activación estimula tres vías de señalización: la vía de la fosfolipasa $A$ (PLA), que genera ácido araquidónico (AA); el eje fosfoinositol 3-kinasa (PI3K)/AKT, que activa la óxido nítrico sintasa constitutiva endotelial (eNOS), y la vía de la fosfolipasa C (PKC), que estimula el calcio intracelular (20). Todo 
lo anterior promueve efectos de vasodilatación, antifibrosis y antinflamatorios. De tal manera, antagoniza el aumento del tono simpático, la vasoconstricción, el incremento de la presión arterial, la fibrosis y la hipertrofia miocárdica $(20-22,33,60)$.

ECA2 se puede encontrar de forma soluble en circulación sanguínea o expresada constitutivamente en varios tipos celulares como: células epiteliales alveolares (o neumocitos tipo II, donde se presenta abundantemente), células epiteliales intestinales, endoteliales venosas y arteriales, musculares lisas arteriales, además de células basales epidérmicas de la piel y en el epitelio escamoso no queratinizado de la mucosa oral, nasal y nasofaríngea $(33,47)$. Adicionalmente, se expresa en riñón, corazón, SNC, testículos, glándulas adrenales, páncreas, músculo esquelético y tejido adiposo $(19,23,28,29)$. Cabe resaltar su ausencia en timo, bazo, nódulos linfáticos, médula ósea y células del sistema inmune (24).

Además de ECA2, se han reportado otros receptores que facilitan la entrada de SARS. CoV-2, entre los cuales se encuentran: CD209L (L-SIGN), CD209 (DC-SIGN), receptores de neuropilina (NRP) y CD147/basigina $(20,25)$. Sin embargo, no utiliza otros receptores de coronavirus como aminopeptidasa N (APN) ni dipeptidil peptidasa-4 (DPP4) (26).

\section{Entrada viral}

La interacción de SARS-CoV-2 con su receptor es mediada por las espigas en su superficie, las cuales, como se mencionó, son homotrímeros de proteína $S$, compuestas por dos subunidades S1 y $S 2(6,26,59,60)$. S1, a su vez, incluye un péptido señal, un dominio N-terminal (NTD) y el dominio de unión al receptor (RBD). Por otra parte, S2 contiene un péptido fusión (FP), heptadas repetitivas 1 y 2 (HR1 y HR2), un dominio transmembrana (TM) y uno citoplasmático (CP) $(3,61)$. Por lo tanto, S1 contribuye a la unión con el receptor, seguido de la fusión de la envoltura viral con la membrana endosomal de la célula huésped por acción de
S2 $(26,59)$. La subunidad S1 puede intercambiar entre dos conformaciones, un estado down, en el que es inaccesible a su receptor y, por lo tanto, sugiere un mecanismo de evasión de respuesta inmune en el huésped, y un estado up, accesible al receptor $(3,30)$.

Posterior a la unión entre el RBD y la ACE2, se genera un clivaje de la proteína $S$ por parte de las proteasas, como la proteasa transmembrana de serina 2 (TMPRSS2), y la subsecuente liberación del péptido fusión, mediado por furinas $(11,31,45,60,62)$. De tal forma, las membranas viral y celular se fusionan y facilitan la entrada del microrganismo por vía endosomal, lo cual inicialmente se da en células epiteliales de las vías respiratorias superiores y demuestra una alta carga viral en la zona y, por tanto, una mayor transmisibilidad $(11,18)$. El sitio de clivaje por furinas (secuencia RPPA) presente en el sitio S1/S2 de SARS-CoV-2 no existe en SARS-CoV, lo que explicaría una endocitosis más efectiva por acción de proteasas de poliproteínas como furina y catepsina. A su vez, aumenta el tropismo, puesto que la catepsina podría ser una proteasa alternativa que permita la entrada y replicación viral en células que no expresan TMPRSS2 $(18,25)$. La unión de la proteína $S$ viral al ACE2 disminuye la expresión del receptor en la membrana celular por dos mecanismos: puede ser escindido por TMPRSS2 y causa internalización del receptor o por la desintegrina y metaloproteinasa 17 (ADAM17), lo cual resulta en ACE2 circulante $(20,24,44,47,63)$.

Una vez en el citoplasma, se realiza la síntesis de poliproteínas 1a/1ab (ppla y pp1ab) a partir del ARN viral, las cuales participan en el proceso de replicación. Por otra parte, la proteína $\mathrm{N}$, además de intervenir en la síntesis de ARN, se encarga del ensamblaje de nuevos viriones que son finalmente liberados $(3,6,11)$. En resumen, el ciclo vital del virus consta de cinco pasos: unión, penetración, biosíntesis, maduración y liberación (25).

Cabe resaltar que la afinidad de SARS-CoV-2 por ECA2 es de 10 a 20 veces mayor que SARS-CoV, lo que puede explicar su mayor transmisibilidad entre humanos $(3,8,29,60)$. Esta 
diferencia entre ambos virus se presenta en los residuos de unión al receptor, puesto que, de 14 aminoácidos que interactúan con ECA2 en SARS-CoV, se conservan ocho en SARS-CoV-2 $(27,41)$. Además, el nuevo coronavirus reconoce la ACE2 no solamente de humanos, sino también de murciélagos, civetas, monos y cerdos, aunque no interactúa con la de los ratones, cuyo receptor difiere en los residuos 82 y 353, necesarios para la unión. Esto demuestra que el SARS-CoV-2 no utiliza otros receptores de $\mathrm{CoV}$ como APN o DPP4 $(27,29,31)$.

\section{Mecanismos de infección}

Debido a la alta similitud entre SARS-CoV y SARS-CoV-2, se han logrado dilucidar múltiples mecanismos de infección del virus en cuestión, que explican la patogénesis del COVID-19. Sin embargo, es posible resumirlos en los siguientes cuatro: toxicidad viral directa, desregulación de la respuesta inmune, daño celular endotelial y tromboinflamación, y desregulación del SRAA (17). Cada uno de estos se explicará profundamente a continuación.

\section{Toxicidad viral directa}

El daño multiorgánico observado en pacientes con COVID-19 puede explicarse, en parte, por el daño tisular directo causado por SARS-CoV-2. Como se ha mencionado, el tropismo del virus no se limita únicamente a las vías respiratoria, sino también a los tejidos renal, miocárdico, neurológico y gastrointestinal. Sin embargo, el mecanismo de diseminación extrapulmonar todavía no se ha dilucidado por completo (17).

Entre los efectos citopáticos directos del virus se encuentran su capacidad de inducir apoptosis, necrosis y piroptosis de células epiteliales alveolares y endoteliales. La piroptosis es un tipo de muerte celular atípica que exhibe características de necrosis y apoptosis, que en SARS resulta de la activación, por parte de la viroporina 3a, del inflamasoma NLRP3 y posterior liberación de IL-1 $\beta(3,7,18,64)$. Se han reportado elevadas concentraciones de IL-1 $\beta$ séricas en pacientes con COVID-19 (3). Todo lo anterior conduce a la producción descontrolada de citocinas proinflamatorias $(7,8)$, lo cual hace parte de la respuesta inmune desregulada. Dicha hiperinflamación fomenta el daño endotelial y resulta en permeabilidad vascular aumentada, exceso de trombina e inhibición de fibrinólisis (9).

\section{Desregulación de la respuesta inmune}

La sobreactivación de la respuesta inmune innata, en un contexto de linfopenia, lleva a hiperinflamación y al síndrome de liberación de citocinas, que caracterizan el cuadro severo de la enfermedad. Entre otros mecanismos que lo explican se encuentran la rápida replicación viral, el antagonismo de la señalización del interferón y la activación de neutrófilos y monocitosmacrófagos (17).

En primer lugar, células de la respuesta inmune innata expresan receptores de reconocimiento de patrones, los cuales reconocen patrones moleculares asociados con patógenos (PAMP) o al peligro (DAMP). De esta forma, receptores de reconocimiento de patrones como TLR3, TLR7, RIG-1 y MDA-5 reconocen virus ARN, que llevan a la producción de interferones tipo I (IFN), como IFN- $\alpha$ e IFN- $\beta$, que bloquean la replicación viral. Sin embargo, SARS-CoV $y$, muy posiblemente SARS-CoV-2, ejercen un antagonismo de la señalización de interferón, retrasando la respuesta antiviral y promoviendo la replicación viral rápida y efectos citopáticos directos (9). Los cambios en la estructura de la proteína orf3a de SARS-CoV-2, en relación con SARS-CoV, le otorga al primero una mayor capacidad de inhibir la producción de IFN tipo I, II y III (18).

Por lo tanto, una respuesta retrasada y desregulada de interferones tipo I, sumado a la liberación de citocinas, quimocinas y DAMP por parte de neumocitos infectados, conllevan un infiltrado excesivo de monocitos/macrófagos y neutrófilos (PMN) en el parénquima pulmonar (9). Dichas células, a su vez, producen más citocinas (IL1- $\beta$, IL-6, TNF- $\alpha$ ) y quimocinas 
y atraen células inflamatorias adicionales, que resultan en hiperinflamación y potencialmente en hipercitocinemia, que llevan a síndrome de distrés respiratorio agudo y falla multiorgánica $(7-9,60,64)$.

En este orden de ideas, Chen et al. (16) reportaron aumentos significativos de IL-6 en pacientes infectados con SARS-CoV-2, quienes además presentaban insuficiencia cardiaca. Dado que el fallecimiento fue causado por miocarditis fulminante y teniendo en cuenta que la hipercitocinemia es uno de los principales mecanismos fisiopatológicos de dicha entidad, se debe estudiar más a profundidad su asociación con COVID-19. No obstante, cabe resaltar la relación que se ha propuesto entre concentraciones altas de IL-6 en suero y peor pronóstico de la enfermedad (17). En contraste con lo anterior, Zheng et al. (14) no detectaron diferencias significativas de IL-6 y TNF- $\alpha$ en pacientes con COVID-19. No obstante, concluyeron que SARS-CoV-2 altera la función de linfocitos TCD4+ y promueve la activación excesiva y posible agotamiento de células TCD8+, lo cual puede resultar en una inmunidad antiviral del huésped disminuida y explicar la progresión severa de algunos casos (14).

Diferentes factores ambientales pueden influenciar los mecanismos de infección del virus y la susceptibilidad del huésped. La temporada de invierno es la época del año cuando se evidencia mayor incidencia de infección por $\mathrm{CoV}$ humanos. En cuanto a SARS-CoV-2, se especula que su viabilidad en gotas es promovida por una baja humedad y una temperatura ambiental disminuida. Dichas condiciones alteran el aclaramiento ciliar y la defensa inmune innata, lo que permite el acceso al tejido pulmonar y la rápida transmisión (12).

En segundo lugar, la respuesta inmune adaptativa dentro del contexto de infección por SARS-CoV-2 se caracteriza por linfopenia de células TCD4+ y TCD8+, que puede explicarse en parte por el efecto citopático directo e inducción de apoptosis a causa de la excesiva liberación de citocinas proinflamatorias $(9,60)$.
Por otra parte, la persistencia de replicación viral e inflamación en algunas personas puede explicarse por el fenómeno de potenciación mediada por anticuerpos (ADE), en el cual se promueve la entrada de complejos virusanticuerpo, a través de la interacción con FcR de las células blanco (7). El mecanismo ADE también es utilizado por el virus del dengue, de la influenza, del Ébola y por el VIH $(7,15)$.

\section{Daño celular endotelial y tromboinflamación}

La inmunotrombosis o tromboinflamación es un proceso que resulta de la interacción entre la hemostasis y la respuesta inmune innata. Plaquetas, factores de coagulación y células como monocitos/macrófagos y PMN forman trombos que evitan la diseminación de patógenos y funcionan como soporte endotelial y sitio de activación de la respuesta inmune innata. Sin embargo, en la COVID-19 se caracteriza por ser una respuesta desregulada, donde el daño endotelial mediado por infección, acompañada de endotelialitis, resultan en la producción excesiva de trombina, inhibición de fibrinólisis y activación de complemento, todo junto da lugar a microangiopatía que contribuye al ARDS inducido por SARS-CoV-2 $(9,17)$.

Por otra parte, la intercomunicación entre plaquetas y neutrófilos, además de la activación de macrófagos, promueve efectos proinflamatorios, entre los que se encuentran: liberación de citocinas proinflamatorias, formación de fibrina y microtrombos, además de trampas extracelulares de neutrófilos $(17,18$, 64). Estos últimos, a su vez, estimulan las vías de coagulación intrínseca y extrínseca, activan el endotelio, las plaquetas y el sistema de complemento, además contienen proteasas que inhiben anticoagulantes endógenos, que aumentan el estado procoagulante $(9,17,18)$.

Asimismo, existe una intercomunicación entre el sistema de coagulación y el sistema del complemento. $\mathrm{Al}$ activarse el complemento, se estimulan cascadas de señalización que resultan en la generación de moléculas bioactivas pleiotrópicas (C3a, C5a) y del complejo de 
ataque a la membrana. C3a y C5a cumplen roles proinflamatorios y procoagulantes. Por un lado, inducen la degranulación de mastocitos y reclutamiento de monocitos/macrófagos y PMN. Por otro, activan plaquetas y células endoteliales, además de aumentar la expresión del factor de Von Willebrand y del factor tisular (9).

Por su parte, las citocinas proinflamatorias (IL-1 $\beta$, IL-6, TNF- $\alpha$ ) regulan al alza factores procoagulantes. Promueven liberación del factor de Von Willebrand, factor tisular y FII/ FIIa, aumentando la generación de trombina y disminuyendo niveles de anticoagulantes endógenos. También activan el endotelio, al aumentar la expresión de NF-kB $(9,18)$. En conjunto, la comunicación entre cada uno de los elementos mencionados (células endoteliales, plaquetas, monocitos/macrófagos, PMN, sistema de complemento y sistema de coagulación) resultan en un estado hipercoagulable (9). Este último, junto a un sistema fibrinolítico agotado, diferencian el ARDS del COVID-19, del ARDS inducido por otros virus respiratorios, como el virus de la influenza (18).

\section{Desregulación del SRAA}

La infección por SARS-CoV-2 media un desbalance del SRAA y, por lo tanto, una alteración de procesos fisiológicos del cuerpo como balance hidroelectrolítico, regulación de la presión arterial, permeabilidad vascular y crecimiento tisular (17). SARS-CoV-2 induce internalización de su receptor ECA2, disminuyendo su actividad y, de esta forma, favorece la relación ECA/ECA2 hacia un predominio de ECA, que genera mayores niveles de Ang II. Lo anterior resulta en vasoconstricción pulmonar, daño orgánico fibrótico, oxidativo e inflamatorio, que culmina, finalmente, en lesión pulmonar aguda y ARDS (9).

\section{Sistema respiratorio}

El pulmón es el órgano más afectado por la COVID-19, no solamente su gran área de superficie lo hace más susceptible a virus inhalados, sino que el $83 \%$ de células que expresan ECA2 corresponden a células epiteliales alveolares tipo II, las cuales, a su vez, contienen múltiples genes relacionados con procesos virales, como replicación, ensamblaje y regulación del ciclo vital (29). El daño viral directo lleva a piroptosis de los neumocitos, que liberan DAMP como moléculas de ATP, olígomeros de ASC y ARN viral, que activan los macrófagos alveolares. Estos últimos secretan quimocinas y citocinas al espacio intersticial, promoviendo la extravasación de granulocitos y linfocitos al parénquima pulmonar para ayudar a combatir la infección. De esta forma, se activan las células de respuesta adaptativa (linfocitos TCD8+, TCD4+, células B) y linfocitos NK, que secretan IFN- $\gamma$, lo que a su vez estimula neutrófilos y macrófagos para secretar aún más mediadores proinflamatorios, que resultan en daño tisular $(26,61)$.

En una persona con una respuesta inmune alterada la respuesta inflamatoria y la secreción de citocinas será exagerada, porque altera la arquitectura pulmonar y promueve el desarrollo de edema y neumonía, además de diseminación viral y de inflamación sistémica. Por otra parte, pacientes con una respuesta inmune intacta construirán una respuesta efectiva y específica contra el SARS-CoV-2, al producir anticuerpos capaces de neutralizar e inactivar el virus. De igual forma, los macrófagos reconocen los virus y las células infectadas y los eliminan a través de fagocitosis. Como el daño pulmonar y la inflamación es mínima y localizada, el individuo pasará a su fase de recuperación y la enfermedad se limitará (61).

Adicionado a lo anterior, una de las peores complicaciones de los pacientes es el síndrome de distrés respiratorio agudo, el cual corresponde a la manifestación más fatal de la lesión pulmonar aguda (33). Un posible mecanismo involucrado en la patogénesis puede ser la regulación a la baja y la internalización de ECA2 por parte del SARS-CoV-2, resultando en la hiperproducción de Ang II por parte de la ECA, con la consecuente estimulación del receptor AGTR1A y una desregulación del SRAA, manifestado en un aumento de la permeabilidad vascular, 
edema, acumulación de neutrófilos y pérdida de función pulmonar $(7,10,27,65)$. Por lo tanto, la ECA2 otorga un efecto protector contra la lesión pulmonar aguda (33).

\section{Sistema cardiovascular}

El principal mecanismo que afecta el sistema cardiovascular es la regulación a la baja de los receptores ECA2, expresados en miocitos, fibroblastos, células endoteliales y células del músculo liso, ya que afecta la acción cardioprotectora de los productos Ang1-7 y Ang1-9 (17,23,43,44). El subsecuente exceso de Ang II promueve hipertensión, trombosis, fibosis cardiaca y lesión pulmonar (47). En general, las manifestaciones cardiacas pueden dividirse en disfunción eléctrica y mecánica. Las arritmias hacen parte del primer grupo, las cuales presentan múltiples mecanismos fisiopatológicos. Por un lado, la acción incrementada del eje AngII-ATR1 altera la iniciación y propagación del potencial de acción a través de la vía de la PKC. Dicho desbalance promueve, a su vez, la activación de la oxidasa de NADPH, que aumenta el estrés oxidativo y los niveles de calcio sarcoplásmico, que intervienen en la despolarización (43). Por otra parte, aumenta el riesgo de arritmias por condiciones como desbalance hidroelectrolítico, hipoxia, estrés inflamatorio y neurohumoral $(43,48,49)$. Asimismo, la miocarditis fulminante a causa del efecto citopático viral directo se relaciona con arritmias, ya que la inflamación miocárdica asociada con necrosis dan lugar a focos de reentrada en el circuito eléctrico cardiaco (49).

En ese orden de ideas, la disfunción mecánica puede subdivirse en daño pericárdico, miocárdico o valvular. La pericarditis se presenta principalmente por exceso de citocinas proinflamatorias, las cuales promueven la inflamación serosa y fibrosis. Al asociarse con derrame pericárdico, puede complicarse a cardiomiopatía de Takotsubo en respuesta al estrés físico $(43,47,49)$. Por su parte, el daño miocárdico se manifiesta como síndrome coronario agudo, miocarditis, falla cardiaca, cardiomiopatía de estrés y shock. La respuesta inmune desregulada contribuye a la disfunción miocárdica al facilitar la liberación de especies reactivas de oxígeno), óxido nítrico y anión superóxido (43). El efecto viral directo genera citotoxicidad mediada por apoptosis, disrupción de proteínas transcripcionales y pérdida de homeostasis celular. La intercomunicación entre ambos mecanismos da lugar a miocarditis y cardiomiopatía $(17,43,49,50)$.

Asimismo, el síndrome coronario agudo y la falla cardiaca se explican por un desbalance entre el aporte y la demanda de oxígeno; el aporte disminuye por la hipoxia secundaria a la lesión pulmonar y la demanda aumenta en respuesta a la infección y la hiperinflamación (43,47-49). Lo anterior se ve exacerbado en el contexto de hipercoagulabilidad, aumento de formación de microtrombos y ruptura de placa ateroesclerótica $(43,48,49)$. Por último, el daño valvular se desarrolla por la regulación a la baja del receptor ECA2, el cual se expresa altamente en fibroblastos estromales de las válvulas cardiacas, especialmente en la válvula aórtica. Dicha depresión potencia la fibrosis y esclerosis valvular, además de retroalimentar positivamente la hiperinflamación, al inducir la secreción de citocinas proinflamatorias y reclutar macrófagos (43).

En resumen, los principales mecanismos involucrados en la fisiopatología del SARS$\mathrm{CoV}-2$ de las complicaciones cardiovasculares incluyen el daño directo a los cardiomiocitos, inflamación sistémica, fibrosis, desestabilización de placa coronaria e hipoxia (51). Cabe resaltar la asociación entre las comorbilidades más influyentes, como la hipertensión arterial y la diabetes mellitus, y un peor pronóstico de la enfermedad. Dichas enfermedades crónicas implican un estado proinflamatorio de base, además de una adaptación inefectiva del sistema cardiovascular frente al aumento de la demanda metabólica $(43,49,50)$. 


\section{Sistema nervioso central}

En el SNC, las células que expresan ECA2 corresponden a neuronas, neuroglía y células del endotelio neurovascular $(28,52)$. La neuroinvasión puede ocurrir por dos grandes mecanismos: hematógeno o neurogénico. La primera vía incluye la penetración directa del virus a través de las células endoteliales de la barrera hematoencefálica (BHE) o utilizando células sanguíneas periféricas que migren desde otras partes del cuerpo hacia el cerebro. La segunda vía hace referencia al transporte axonal retrógrado, a través del nervio olfatorio o del nervio vago $(17,53,58,64)$.

En ese orden de ideas, las manifestaciones neurológicas se dividen en centrales y periféricas. Las primeras incluyen cefalea, encefalopatía, delírium, convulsiones, accidente cerebrovascular, encefalitis y autoinmunidad parainfecciosa. Por otra parte, las periféricas aluden a disfunciones aisladas de pares craneales (anosmia y ageusia), síndrome de Guillain-Barré y miositis (52).

A nivel central, los mecanismos fisiopatológicos que más se relacionan con dichas presentaciones son respuesta inmune innata desregulada, lo cual lleva a la migración de citocinas proinflamatorias desde la periferia hacia la microvasculatura cerebral, donde ejercen un daño directo y disrupción de la BHE; además, activan la microglía, promoviendo un mayor daño de la BHE $(17,52)$. Este efecto es causado por el daño viral directo en las células endoteliales neurovasculares y por la migración de células inmunes hacia el parénquima cerebral. Todo lo anterior resulta en alteración de la autorregulación endotelial, hipoperfusión cerebral y neuroinflamación (52). Por otra parte, la regulación a la baja de ECA2 mediado por la unión del SARS-CoV-2 a su receptor genera año endotelial difuso, hiperpermeabilidad, activación de cascada de coagulación y síndrome de disfunción multiorgánica $(17,52)$.

En cuanto a las manifestaciones periféricas, la anosmia puede explicarse por diversos mecanismos: inflamación nasal difusa que genera obstrucción o infección de células no neuronales del epitelio olfatorio que producen desbalances iónicos que inhiben la señalización olfatoria o producen muerte de las neuronas olfatorias. Asimismo, las citocinas proinflamatorias inhiben directamente o indirectamente la función de las neuronas olfatorias, las cuales también pueden sufrir daño citopático directo. Por otra parte, la ageusia es resultado de la infección directa de células linguales o por efecto indirecto de las citocinas proinflamatorias sobre los respectivos nervios $(17,54)$. Por último, el síndrome de Guilláin-Barré se asocia con daño viral directo o indirecto por inflamación (55).

\section{Posible diseminación a otros tejidos y su efecto}

La alta distribución de ECA2 en los tejidos no solamente explica la disfunción multiórganica observada en pacientes complicados con COVID-19, sino que también implica un extenso tropismo del virus con las subsecuentes manifestaciones, aún por dilucidar.

En cuanto al sistema gastrointestinal, en la superficie luminal de las células epiteliales intestinales, la ECA2 funciona como correceptor para la absorción de nutrientes; por lo tanto, uno de los mecanismos implicados incluye la lesión viral directa $(17,29)$. Asimismo, el daño microvascular contribuye al desarrollo de isquemia mesentérica; la hiperinflamación da lugar a daño tisular y la alteración de la flora intestinal permite una progresión más severa de la enfermedad (17). Se ha detectado presencia de SARS-CoV-2 en el tubo gastrointestinal y heces, lo que sugiere una probable vía de infección inicial, la posible transmisión fecal-oral de SARSCoV-2 y se relaciona con la aparición de diarrea como parte de algunos síntomas comunes $(29,35,37)$. En relación con los pacientes con enfermedad inflamatoria intestinal, estos no se encuentran en mayor riesgo de severidad, ya que, aunque presentan una concentración de ECA2 incrementada, corresponde principalmente a la forma soluble de la enzima, que actúa como interceptor competitivo del virus (42). 
En el sistema endocrino, el receptor ECA2 se expresa en las células $\beta$-pancreáticas. Por lo tanto, la lesión viral directa acompañada del exceso de citocinas proinflamatorias contribuyen a la apoptosis de dichas células, la subsecuente deficiencia de insulina e hiperglucemia (17). La diabetes mellitus constituye un factor de riesgo importante, ya que implica una respuesta inmune alterada, incremento de hormonas contrarreguladoras que promueven la gluconeogénesis hepática, reducción en la secreción de insulina, resistencia a esta y cetogénesis $(11,17)$. Por otra parte, la obesidad supone una función pulmonar alterada al presentar volúmenes y distensibilidad pulmonar reducidos, al igual que un aumento de la resistencia de la vía aérea. De igual forma, el exceso de adiposidad incrementa la liberación de citocinas proinflamatorias (17).

En la sistema hematológico, la linfopenia se manifiesta a causa de la citotoxicidad directa del virus, que lleva a depleción de linfocitos mediada por apoptosis $(17,56)$. La leucocitosis, principalmente neutrofilia, es consecuencia de la respuesta hiperinflamatoria, lo cual también explica las complicaciones tromboembólicas, en asociación con la hipoxia y el daño directo. La expresión aumentada de ECA2 en células perpetúa un círculo vicioso de endotelialitis que promueve la tromboinflamación desregulada (17).

En el riñón, la principal complicación a causa de la COVID-19 es la insuficiencia renal aguda, la cual se explica fisiopatológicamente por los cuatro mecanismos mencionados. En primer lugar, se genera un daño citopático directo posibilitado por la expresión de receptores ECA2 en el epitelio tubular proximal renal y los podocitos (45-47). De hecho, una secuenciación reciente de ARN tisular humano demostró que la expresión renal de ECA2 es 100 veces más alta que en el tejido pulmonar. Por otra parte, la desregulación del SRAA promueve la inflamación, fibrosis y vasoconstricción glomerular $(45,46)$. En cuanto a la hipercitocinemia induce disfunción tubular y endotelial, la IL-6 aumenta la permeabilidad vascular renal y participa en la disfunción microcirculatoria. Por último, la trombosis microvascular contribuye en la alteración de la microcirculación renal y en el desarrollo de insuficiencia renal aguda a causa de la desregulación de la homeostasis de la coagulación (46,47).

Por último, los mecanismos que contribuyen a las manifestaciones de erupción cutánea y dermatitis incluyen la hipersensibilidad frente al ARN viral, el síndrome de liberación de citocinas, el depósito de microtrombos y la subsecuente vasculitis (17).

\section{Conclusión}

La pandemia de COVID-19 es de gran interés en la actualidad, por sus importantes implicaciones no solamente en el contexto la de la salud, sino también en los ámbitos económico, social y cultural, que tienen al mundo paralizado. Por lo anterior, urge un mejor un entendimiento del virus que permita idear efectivas estrategias de promoción, prevención y tratamiento.

A lo largo del artículo se resumieron datos clave sobre el genoma y la estructura del virus, su receptor celular y sus efectos sobre el sistema inmune y otros tejidos corporales. El SARS$\mathrm{CoV}-2$ es un virus que ha presentado importantes mutaciones y recombinación genética, lo cual le ha permitido evolucionar y mejorar su capacidad patogénica y vías de transmisión. Los diferentes grados de severidad de la enfermedad se explican por factores del virus, pero también por comorbilidades de los individuos que los hacen más susceptibles a desencadenar respuestas inflamatorias descontroladas, como hipercitocinemia, además de promover un estado de inflamación perpetuado por complejos virusanticuerpo y una posible potenciación mediada por el fenómeno ADE.

Cabe resaltar, que el receptor celular ECA2 desempeña un papel fundamental no solo en la internalización del virus, sino también en la decisiva progresión hacia manifestaciones leves o graves, esto debido a su extensa distribución en el organismo y su función órgano-protectora. Con respecto a lo anterior, aún no se han dilucidado 
por completo las acciones del virus sobre otros tejidos, aunque existe evidencia de su presencia en el SNC, que debe llamar la atención para futura profundización.

\section{Recomendaciones}

Se recomienda hacer estudios que expliquen la patogénesis viral en células diferentes a las del epitelio pulmonar, teniendo en cuenta la diseminación comprobada hacia el SNC, el riñón, el corazón y el endotelio, para comprender la implicación clínica de las complicaciones y lograr predecir el pronóstico de individuos que son más susceptibles a estas.

\section{Consideraciones éticas}

Se declara que la presente revisión cumple con los criterios éticos en investigación biomédica.

\section{Financiamiento}

La presente revisión se realiza sin financiamiento externo.

\section{Conflicto de intereses}

Las autoras del presente artículo hacen constar que no existe, de manera directa o indirecta, ningún tipo de confluencia de intereses que pueda poner en peligro la validez de lo comunicado.

\section{Referencias}

1. Chen N, Zhou M, Dong X, Qu J, Gong F, Han Y, et al. Epidemiological and clinical characteristics of 99 cases of 2019 novel coronavirus pneumonia in Wuhan, China: a descriptive study. Lancet. 2020;395(10223):507-13.

2. Li G, Fan Y, Lai Y, Han T, Li Z, Wang W, et al. Coronavirus infections and immune responses. J Med Virol. 2020;92:424-32.

3. Yang $\mathrm{Y}$, Peng $\mathrm{F}$, Wang $\mathrm{R}$, Guan K, Jiang T, Xu G, et al. The deadly coronaviruses: the 2003 SARS pandemic and the 2020 novel coronavirus epidemic in China. J Autoimmun. 2020; 109:1-16. https://d oi.org/10.1016/j.jaut.2020.102434

4. Worldometer. COVID-19 coronavirus pandemic [internet]. 2020 [citado 2020 nov 27]. Disponible en: https://www.worldometers.info/cor onavirus/

5. World Health Organization. Naming the coronavirus disease (COVID-19) and the virus that causes it [internet]. 2020. Disponible en: https://www.who.int/emergencies/ diseases/novel-coronavirus-2019/tech nical-guidance/naming-the-coronaviru $s$-disease-(covid-2019)-and-the-virus- $t$ hat-causes-it

6. Cascella $\mathrm{M}$, Rajnik $\mathrm{M}$, Cuomo A, Dulebohn SC, Napoli $\mathrm{R}$ Di. Features, evaluation and treatment coronavirus (COVID-19). En: StatPearls [internet]. Treasure Island (FL): StatPearls Publishing; 2020. Disponible en: https://www.ncbi. nlm.nih.gov/books/NBK554776/

7. Fu Y, Cheng Y, Wu Y. Understanding SARS-CoV-2-mediated inflammatory responses: from mechanisms to potential therapeutic tools. Virol. 2020;35:266-71. https://doi.org/10.100 7/s12250-020-00207-4

8. Li $\mathrm{H}$, Liu $\mathrm{S}, \mathrm{Yu} \mathrm{X}$, Tang $\mathrm{S}$, Tang C. Coronavirus disease 2019 (COVID-19): current status and future perspective. Int J Antimicrob Agents. 2020;55(5):105951. https://doi.org/10. 1016/j.ijantimicag.2020.105951

9. Henry BM, Vikse J, Benoit S, Favaloro EJ, Lippi G. Hyperinflammation and 
derangement of renin-angiotensinaldosterone system in COVID-19: a novel hypothesis for clinically suspected hypercoagulopathy and microvascular immunothrombosis. Clin Chim Acta. 2020;507:167-73.

10. Ingraham NE, Barakat AG, Reilkoff R, Bezdicek T, Schacker T, Chipman JG, et al. Understanding the renin-angiotensinaldosterone-SARS-CoV axis: a comprehensive review. Eur Respir J. 2020;56:2000912. http://dx.doi.org/10. 1183/13993003.00912-2020

11. Muniyappa R, Gubbi S. Perspective: COVID-19 pandemic, corona viruses, and diabetes mellitus. Am J Physiol. 2020;318:736-41.

12. Moriyama M, Hugentobler WJ, Iwasaki A. Seasonality of respiratory viral infections. Annu Rev Virol. 2020;7:83-101.

13. Guo L, Ren L, Yang S, Xiao M, Chang D, Yang F, et al. Profiling early humoral response to diagnose novel coronavirus disease (COVID-19). Clin Infect Dis. 2020;71(15):778-85.

14. Zheng $\mathrm{H}$, Zhang $\mathrm{M}$, Yang $\mathrm{C}$, Zhang N, Wang $\mathrm{X}$, Yang $\mathrm{X}$, et al. Elevated exhaustion levels and reduced functional diversity of $\mathrm{T}$ cells in peripheral blood may predict severe progression in COVID-19 patients. Cell Mol Immunol. 2020;17:541-3.

15. Yip MS, Cheung CY, Li PH, Bruzzone R, Peiris JSM, Jaume M. Investigation of Antibody-Dependent Enhancement (ADE) of SARS coronavirus infection and its role in pathogenesis of SARS. BioMed Cent. 2011;5(1):80.

16. Chen C, Zhou Y, Wang DW. SARS-CoV-2: a potential novel etiology of fulminant myocarditis. Herz. 2020;45:230-2.
17. Gupta A, Madhavan MV, Sehgal K, Nair N, Mahajan S, Sehrawat TS, et al. Extrapulmonary manifestations of COVID-19. Nat Med. 2020;26(7):1017-32. http://dx.d oi.org/10.1038/s41591-020-0968-3

18. Morris G, Bortolasci CC, Puri BK, Olive L, Marx W. The pathophysiology of SARS-CoV-2: a suggested model and therapeutic approach. Life Sci. 2020;258:118166.

19. Wiese O, Zemlin AE, Pillay TS. Molecules in pathogenesis: angiotensin converting enzyme 2 (ACE2). J Clin Pathol. 2020;0:1-6.

20. Amraei R, Rahimi N. COVID-19, renin-angiotensin system and endothelial dysfunction. Cells. 2020;9(7):1-18.

21. Mirabito Colafella KM, Uijl E, Danser J. Interference with the renin-angiotensin system (RAS): classical inhibitors and novel approaches. En Reference Module in Biomedical Sciences: Encyclopedia of Endocrine Diseases. 2nd ed. Elsevier. 2018 https://doi.org/10.1016/B978-0-1 2-801238-3.65341-2

22. Vaduganathan $M$, Vardeny $O$, Michel T, Mcmurray JJ V, Pfeffer MA, Solomon SD. Special report renin-angiotensin-aldosterone system inhibitors in patients with covid-19. N Engl J Med. 2020;382:1653-9.

23. Dalan R, Bornstein SR, Elarmouche A, Rodionov RN, Markov A, Wielockx B, et al. The ACE-2 in COVID-19: foe or friend? Horm Metab Res. 2020;52:257-63.

24. Xiao L, Sakagami H, Miwa N. ACE2: the key molecule for understanding the pathophysiology of severe and critical conditions of COVID-19: demon or angel? Viruses. 2020;12(5):2002-3. 
25. Yuki K, Fujiogi $M$, Koutsogiannaki S. COVID-19 pathophysiology: a review. Clin Immunol. 2020;215:108427.

26. Chakraborty S, Basu A. The COVID-19 pandemic: catching up with the cataclysm. F1000Research. 2020;9:1-14.

27. $\mathrm{Xu} \mathrm{J,} \mathrm{Zhao} \mathrm{S,} \mathrm{Teng} \mathrm{T,}$ Abdalla AE, Zhu W, Xie L, Wang Y, Guo X. Systematic comparison of two animal-to-human transmitted human coronaviruses: SARS-CoV-2 and SARS-CoV. Viruses. 2020;12(2):244-61. https://doi.org/10. $3390 / v 12020244$

28. Baig AM, Khaleeq A, Ali U, Syeda $\mathrm{H}$. Evidence of the COVID-19 virus targeting the CNS: tissue distribution, host-virus interaction, and proposed neurotropic mechanisms. ACS Chem Neurosci. 2020;11(7):995-8.

29. Zhang $\mathrm{H}$, Penninger JM, Li Y, Zhong N, Slutsky AS. Angiotensin\#converting enzyme 2 (ACE2) as a SARS\#CoV\#2 receptor: molecular mechanisms and potential therapeutic target. Intensive Care Med. 2020;46(4):586-90. https://doi.or g/10.1007/s00134-020-05985-9

30. Shang J, Wan Y, Liu C, Yount B, Gully K, Yang Y, et al. Structure of mouse coronavirus spike protein complexed with receptor reveals mechanism for viral entry. Plos Pathog. 2020;16(3):1-19. http://dx.doi.org/10. 1371/journal.ppat.1008392

31. Li J, You Z, Wang Q, Zhou Z, Qiu Y, Luo R, et al. The epidemic of 2019-novel-coronavirus (2019-nCoV) pneumonia and insights for emerging infectious diseases in the future. Microbes Infect. 2020;22(2):80-5. https://doi.org/10.10 16/j.micinf.2020.02.002
32. Zhang C, Zheng W, Huang X, Bell EW, Zhou X, Zhang Y. Protein structure and sequence reanalysis of 2019-nCoV genome refutes snakes as its intermediate host and the unique similarity between its spike protein insertions and HIV-1. J Proteome Res. 2020;19(4):1351-60.

33. Cheng $\mathrm{H}$, Wang $\mathrm{Y}$, Wang G. Organ-protective effect of angiotensinconverting enzyme 2 and its effect on the prognosis of COVID-19. J Med Virol. 2020;92 (7):726-30.

34. Tilocca B, Soggiu A, Musella V, Britti D, Urbani A, Roncada P. Molecular basis of COVID-19 relationships in different species: a one health perspective. Microbes Infect. 2020;22 (4-5):218-20. https://doi.org/1 0.1016/j.micinf.2020.03.002

35. Wang L, Wang Y, Ye D, Liu Q. A review of the 2019 novel coronavirus (COVID-19) based on current evidence. Int J Antimicrob Agents. 2020;55(6):105948. https://doi.org/10. 1016/j.ijantimicag.2020.105948

36. Srinivasan S, Cui H, Gao Z, Liu M, Lu S, Mkandawire $\mathrm{W}$, et al. Structural genomics of SARS-CoV-2 indicates evolutionary conserved functional regions of viral proteins. Viruses. 2020;12(360):1-17. h ttps://doi.org/10.3390/v12040360

37. Khan S, Siddique R, Shereen MA, Ali A, Liu J, Bai Q, et al. The emergence of a novel coronavirus (SARS-CoV-2), their biology and therapeutic options. J Clin Microbiol. 2020;58(5):187-20. https://doi.org/10. 1128/JCM.00187-20

38. Islam H, Rahman A, Masud J, Shweta DS, Araf Y, Ullah MA, et al. A generalized overview of SARS-COV-2: Where does the current knowledge stand? Electron J Gen Med. 2020;17(6):3-21. 
39. Ceraolo C, Giorgi FM. Genomic variance of the 2019nCoV coronavirus. J Med Virol. 2020;92:522-8.

40. Benvenuto D, Angeletti S, Giovanetti M, Ciccozzi A, Spoto S, Ciccozzi M. The 2019-new coronavirus epidemic: evidence for virus evolution. J Med Virol. 2020;92 (4):455-9.

41. Sohrabi C, Alsafi Z, Neill NO, Khan M, Kerwan A, Al-jabir A, et al. World Health Organization declares global emergency: a review of the 2019 novel coronavirus (COVID-19). Int J Surg. 2020;76:71-6. https://doi.org/10. 1016/j.ijsu.2020.02.034

42. Monteleone G, Ardizzone S. Are patients with inflammatory bowel disease at increased risk for covid-19 infection? J Crohn's Colitis. 2020;14(9):1334-6.

43. Sattar Y, Ullah W, Rauf $\mathrm{H}$, Virk $\mathrm{H}$ ul $\mathrm{H}$, Yadav $\mathrm{S}$, Chowdhury M, et al. COVID-19 cardiovascular epidemiology, cellular pathogenesis, clinical manifestations and management. IJC Hear Vasc. 2020;29:100589. https://doi.org/10.10 16/j.ijcha.2020.100589

44. Barillà F, Bassareo PP, Calcaterra G, Romeo F, Mehta JL. Focus on clinical practice: angiotensinconverting enzyme 2 and corona virus disease 2019: pathophysiology and clinical implications. J Cardiovasc Med. 2020;21(9):630-3.

45. Cano F, Gajardo M, Freundlich $\mathrm{M}$. Renin angiotensin axis, angiotensin converting enzyme 2 and coronavirus. Rev Chil Pediatr. 2020;91(3):330-8.

46. Gabarre P, Dumas G, Dupont T, Darmon M, Azoulay E, Zafrani L. Acute kidney injury in critically ill patients with COVID-19. Intensive Care Med. 2020; 46(7):1339-48. https: //doi.org/10.1007/s00134-020-06153-9
47. Zhyvotovska A, Yusupov D, Foronjy R, Nakeshbandi M, McFarlane SI, Salifu M. Insights into potential mechanisms of injury and treatment targets in COVID-19, SARS-Cov-2 infection. Int J Clin Res Trials. 2020;5(1):1-17.

48. Kwenandar F, Japar KV, Damay V, Hariyanto TI, Tanaka M, Lugito $\mathrm{NPH}$, et al. Coronavirus disease 2019 and cardiovascular system: a narrative review. IJC Hear Vasc. 2020; 29:100557. https://doi.org/10.1016/j.ij cha.2020.100557

49. Azevedo RB, Botelho BG, Hollanda JVG de, Ferreira LVL, Junqueira de Andrade LZ, Oei SSML, et al. Covid-19 and the cardiovascular system: a comprehensive review. J Hum Hypertens. 2020;35:4-11. http://dx.doi .org/10.1038/s41371-020-0387-4

50. Babapoor-Farrokhran S, Gill D, Walker J, Rasekhi RT, Bozorgnia B, Amanullah A. Myocardial injury and COVID-19: possible mechanisms. Life Sci. 2020;253:117723. https://doi.org/1 0.1016/j.lfs.2020.117723

51. Turshudzhyan A. Severe acute respiratory syndrome coronavirus 2 (SARS-CoV-2)-induced cardiovascular syndrome: etiology, outcomes, and management. Cureus. 2020;2(6):1-5.

52. Najjar S, Najjar A, Chong DJ, Pramanik BK, Kirsch C, Kuzniecky RI, et al. Central nervous system complications associated with SARSCoV-2 infection: integrative concepts of pathophysiology and case reports. J Neuroinflammation. 2020;17(1):1-14. 53. Cataldi M, Pignataro G, Taglialatela M. Neurobiology of coronaviruses: potential relevance for COVID-19. Neurobiol Dis. 2020;143:105007. http s://doi.org/10.1016/j.nbd.2020.105007 
54. Ramanathan K, Antognini D, Combes A, Paden M, Zakhary B, Ogino $\mathrm{M}$, et al. COVID-19 and the chemical senses: supporting players take center stage. Neuron. 2020;107:219-33.

55. Rahimi K. Guillain-Barre syndrome during COVID-19 pandemic: an overview of the reports. Neurol Sci. 2020;41(11):3149-56.

56. Martins-Filho P, Santos Souza Tavares C, Santos V. Factors associated with mortality in patients with COVID-19. A quantitative evidence synthesis of clinical and laboratory data. Eur J Intern Med. 2020;76:97-99. https://doi.org/10.1016 /j.ejim.2020.04.043

57. Ilias I, Zabuliene L. Hyperglycemia and the novel covid-19 infection: possible pathophysiologic mechanisms. Med Hypotheses. 2020;139:109699. https://doi.org/10.1 016/j.mehy.2020.109699

58. Wu Y, Xu X, Chen Z, Duan J, Hashimoto $K$, Yang $L$, et al. Nervous system involvement after infection with COVID-19 and other coronaviruses. Brain Behav Immun. 2020;87:18-22. https://doi.org/10.1016 j.bbi.2020.03.031

59. Mehmood I, Ijaz M, Ahmad S, Ahmed T, Bari A, Abro A, et al. SarsCov-2: An update on genomics, risk assessment, potential therapeutics and vaccine development. Int J Environ Res Public Health. 2021;18(4):1-23.

60. Triggle CR, Bansal D, Ding $\mathrm{H}$, Islam MM, Farag EABA, Hadi $\mathrm{HA}$, et al. A Comprehensive review of viral characteristics, transmission, pathophysiology, immune response, and management of SARS-CoV-2 and COVID-19 as a basis for controlling the pandemic. Front Immunol. 2021;12(631139):1-23. https://doi.org/ 10.3389/fimmu.2021.631139
61. Tay MZ, Poh CM, Rénia L, Macary PA, Ng LFP. The trinity of COVID-19: immunity, inflammation and intervention. Nat Rev Immunol. 2020;20(6):363-74.

62. Lippi G, Sanchis-Gomar F, Henry BM. COVID-19: unravelling the clinical progression of nature's virtually perfect biological weapon. Ann Transl Med. 2020;8(11):693.

63. Zamai L. The Yin and Yang of ACE / ACE2 pathways: the rationale for the use of renin-angiotensin system inhibitors in COVID-19 patients. Cells. 2020;9(7):1704.

64. Cunha L, Lopes T, Prudencio de Araujo L, Vieira de Oliveira Rosario L, Pereira Ferrer V. Endothelial cells and SARS-CoV-2: an intimate relationship. Vascul Pharmacol. 2021;137(106829):1-12. https://doi.or $\mathrm{g} / 10.1016 /$ j.vph.2021.106829

65. Bahat G. COVID-19 and the renin angiotensin system: implications for the older adults. J Nutr Heal Aging. 2020;24(7):699-704. https://doi.org/10 .1007/s12603-020-1403-7 